\title{
20 Data-driven urbanism, digital platforms, and the planning of MaaS in times of deep uncertainty: What does it mean for CAVs?
}

Ian Banerjee, Peraphan Jittrapirom, Jens S. Dangschat

1. Introduction $\quad \mathbf{4 4 2}$

1.1 Background $\quad 442$

1.2 The fourfold process: Mental map of the data-driven city 443

2. Data-driven urbanism

2.1 "Code/spaces": Building blocks of the cyber-physical landscape 445

2.2 Digitalization and big data 445

2.3 The data-driven city 445

2.4 The computational understanding of the city and its complications 447

2.5 Regulating the data-driven city 448

2.6 Governance: Examples of alternative approaches 449

$\begin{array}{ll}\text { 3. Digital Platforms } & \mathbf{4 5 0}\end{array}$

3.1 Rise of the platform society 450

3.2 From "smart urbanism" to "platform urbanism" 451

3.3 The problem of platforms and the challenge of their regulation 451

$\begin{array}{lll}3.4 & \text { Digital transport platforms } & 457\end{array}$

4. The case of MaaS: Planning in times of deep uncertainty 458

4.1 MaaS: Benefits and challenges 458

4.2 Pilot projects and schemes of MaaS: Government as a central actor 459

4.3 Planning MaaS during deep uncertainty 461

5. What does this mean for CAVs?

5.1 Comprehensive planning 462

5.2 Public value-centric design: Three critical questions 462

$\begin{array}{ll}\text { 6. Conclusion } & 463\end{array}$

$\begin{array}{ll}\text { Literature } & 466\end{array}$

Peraphan Jittrapirom

Nijmegen School of Management, Radboud University and Global Carbon Project (GCP), National Institute for Environmental Studies (NIES)

P.jittrapirom@fm.ru.nl
Ian Banerjee

TU Wien, Research Unit of Sociology (ISRA) ian.banerjee71@gmail.com

Jens S. Dangschat

TU Wien, Research Unit of Sociology (ISRA)

jens.dangschat@tuwien.ac.at 


\section{INTRODUCTION}

This paper offers a critical review of three coevolving socio-technical paradigms: (a) "data-driven urbanism," (b) digital platforms, and (c) "Mobility-as-a-Service" (MaaS). It explores the complex relationship unfolding between data-driven cities and digital platforms, while drawing on MaaS as a case to discuss the challenges of implementing mobility services via digital platforms. Inferences are drawn from the ongoing debate accompanying these three paradigms to identify potential criteria for the design of socially accountable governance models for the deployment of connected and automated vehicles (CAVs). Grounded in current trends, the research builds on the assumption that CAV-based transport services will be offered through digital platforms of some sort in the future. Also based on this assumption, we believe that if national governments and municipalities are interested in deploying CAVs, they will be well advised to learn from the experience gained from the practices of these three emerging paradigms.

Complying with the overall aspiration of this publication, we are eager to move away from understanding CAVs as a game-changing techno-economic novelty and toward understanding it as a socio-technical innovation that might help us to design sustainable, inclusive, and participatory human environments. To achieve this, we argue it is indispensable to understand the geography, architecture, and "logic" of the emerging cyber-physical landscape produced by the interweaving of physical and digital formations and the practices of data-driven cities, of which CAVs will potentially be constitutive elements (see fig. 1).

The first section of this paper reflects on the technological, conceptual, and epistemological shifts taking place in the discourse and practices of data-driven urbanism by highlighting the growing influence of big data and the computational understanding of the city. The second section looks at how online platforms are making use of big data and ingenious digital mechanisms to create ever-new forms of commercial services. It looks at the key challenges that surround their emerging practices. The third section looks at the challenge of planning MaaS under deep uncertainty. Apart from its technological feasibility, MaaS is associated with various uncertainties concerning issues, such as network effects and questions around how it will affect the overall transportation system, future demand, and the willingness of crucial stakeholders to cooperate (Jittrapirom et al. 2017a). Finally, the fourth section draws inferences from an analysis of the debate unfolding around the three paradigms mentioned above, and makes recommendations for the regulation, governance, and design of potential CAV platforms.

\subsection{BACKGROUND}

The growing capacity to capture and intelligently process vast amounts of data lies at the center of the data-driven city paradigm (Kitchin 2014, Leszczynski 2016). The intensifying relationship between new data regimes and city organization is increasingly leading to the emergence of practices in urban governance that primarily engage in the collection, management, and commodification of voluminous amounts of varied, dynamic, and interoperable data. Hopes placed on the data-driven city, popularly called the "smart city," revolve largely around the narratives of efficiency, economic opportunity, safety, and sustainability. All aspects of contemporary life in the modern world are affected by the shift toward this data-based reorganization of activities and services-from mobility to education, from health to administration, from retail to energy. 
An essential driver of this shift is the promise of securitization and enhanced quality of public life through increasingly centralized decision-making processes and service provision with the help of artificial intelligence (AI) and automation (see Mitteregger in this volume...). The digitized notion of urban governance is based largely on new forms of predictive analytics, enabled first by the technological feasibility of capturing large amounts of socio-spatial data drawn from surveillance cameras and other sensors built in the city's infrastructures, and second by the possibility of deriving meaningful patterns of prognostic material from them. In addition to the collection of infrastructural data, increasing amounts of personal data are being captured by digital platforms. These entities use automated mechanisms to extract large volumes of specified personal data from the depths of digital space and provide users of this same space with increasing varieties of value-added services. The intelligent processing of real-time personal data of various formats is now making it possible to create lenses of what is sometimes called "sentiment analytics" (Leszczynski 2016, Bassoo et al. 2017). These are automated learning algorithms deployed to analyze and predict various patterns of human behavior. The interoperability between these highly heterogeneous types of collected data and the convergence of different types of analytics has opened up unprecedented possibilities of new forms of organization but also control of everyday life. This has also resuscitated the notion of a "computational understanding" of the city-an idea that had already entered the urban imagination back in the 1950s (Hall 2002, Shelton et al. 2015).

The rapid proliferation of trans-local digital platforms and their high degree of penetration into all spheres of society are making them more and more indispensable for the functioning of contemporary cities. Their capacity to replace pre-digital, offline organizations have turned them into powerful agents of structural change. However, while they are benefiting society in innumerable ways, the untransparent practices of their globally operating commercial inflections have recently led to intense legal disputes (see 3.3) across continental borders. Regulators, particularly in Europe, are confronted with a plethora of new challenges associated with their social impact, citizens' acceptance, technological complexities, legal ambivalences, and geopolitical consequences. Since the public sector and governments are increasingly reliant on corporate platforms, it is crucial to rethink the principles on which the design of these systems is based if we have the desire to sustain democratic values and guarantee an equal playing field for all. We assert that designing governance models in the digital age will to a great degree be about governing the practices of data-driven cities and digital platforms. This paper identifies the main challenges facing the regulation of these formations and the prospects of designing governance models that will engender benefits to the whole of society. The key challenges identified in this review are the question of how to instigate a broad societal discourse on the topic and how to enshrine public values into the elusive architecture of these digital formations.

\subsection{THE FOURFOLD PROCESS: MENTAL MAP OF THE DATA-DRIVEN CITY}

It is fairly evident by now that digital platforms will play a crucial part in the creation of new types of digital infrastructures that will shape the future of cities. A growing volume of literature on "platform urbanism" (Barns 2014, Bratton 2016, Langley/Leyshon 2017, Srnicek 2017, Artioli 2018, Söderstörm/Mermet 2020) indicates that there is increasing academic interest in the dynamics that are emerging between the socio-technical formation of digital platforms and the urban.

Drawing from this literature, we outline a mental map of the main underlying dynamics producing the cyber-physical landscapes of the data-driven city. It depicts a fourfold movement comprising (a) the collection of unprecedented amounts of infrastructural and personal data captured in physical and digital spaces, (b) the storage of collected data, (c) the processing of 
collected data to derive meaning and to simultaneously create economic or societal value out of them, and (d) feeding back the created values into the materialities of everyday life in the form of services. This process is largely orchestrated by digital platforms (see 3.3.2) with the help of digital information systems, automated algorithms, and Al. MaaS, CAVs, the Internet of Things (IOT), etc., are seen as constitutive elements in the incessant movement of this fourfold process.

Figure 1.: Mental map of the production of cyber-physical landscapes in the data-driven city (fourfold movement). Physical objects and digital systems merge here to produce new realities and imaginaries of the urban. Digital platforms play a pivotal role in this process, while MaaS, CAVs, loT, etc., are seen as its constitutive elements.

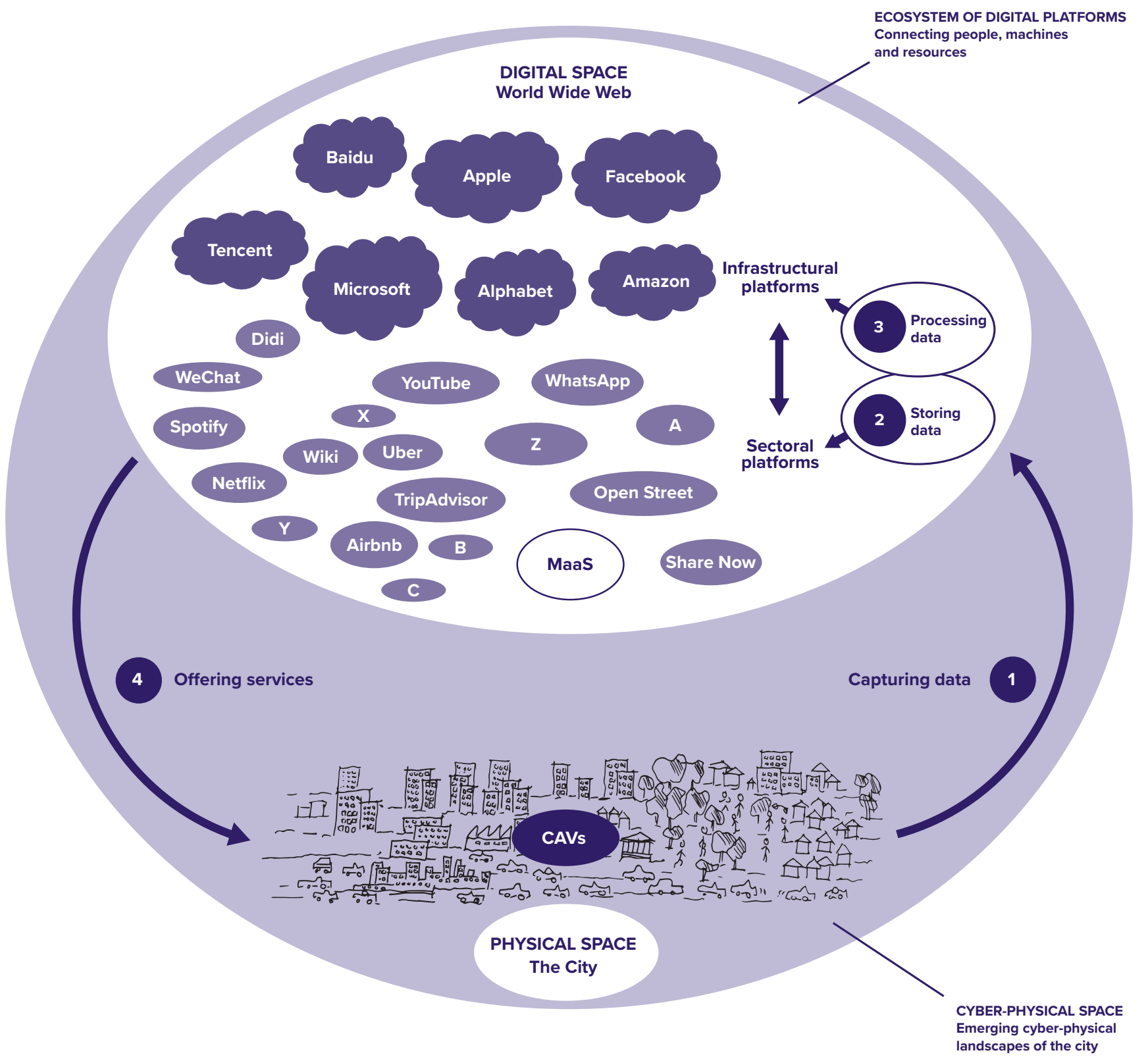

Source: Ian Banerjee 


\section{DATA-DRIVEN URBANISM}

\section{1 “CODE/SPACES”: BUILDING BLOCKS OF THE CYBER-PHYSICAL LANDSCAPE}

Two highly complex, contingent, and open systems-cities and digital information systems-are currently being interwoven fig. 1) to create a novel and vast landscape of cyber-physical materialities (Townsend 2013). Dodge and Kitchin (2004) describe spaces wherein software and the spatiality of everyday life become mutually constituted as "code/spaces." For example, the connected car is not just a car, it is a code/space embedded in large networks of various informational exchanges enabled by codes and algorithms-networks that Manuel Castells famously called "spaces of flow" (Castells 1996). The ontologies of hybrid forms of single code/spaces, connected with thousands of other code/spaces, are challenging our very understanding of objects, urban processes, and human agency. The amalgamation of digital and physical spaces has reached a size and degree of sophistication that makes the invisible architecture of the World Wide Web as important as the visible architecture of the physical world-indeed in some cases, it seems, it has become more important.

\subsection{DIGITALIZATION AND BIG DATA}

To encapsulate the new discourse emerging around the broad notion of data-driven urbanism, it is helpful to look at the emergence of two important terms: big data and digitalization. Today technological change is mostly associated with digitalization, a process that has arguably brought about the most sweeping transformative changes to society since the industrial revolution. Central to all digitalization processes lies the technological capacity to capture and convert all data into binary information and to process them to generate economic or social values. These units of binary data are emerging as the new constitutive elements of all significant flows and activities of human civilization. Big data, a term popularized by John Mashey in the 1990s (Kitchin/Gavin 2016), refers to very large or complex sets of data that can be captured, stored, and analyzed through data-processing mechanisms (Kitchin/Gavin 2016).

The term often refers to the traces created in digital space from the activities, transactions, and movements of millions of users and objects. Small data, in contrast, is the data collected from sources such as questionnaires, city audits, ethnographies, etc. Literature on the features of big data commonly refers to the three "Vs": (

1. volume: consisting of petabytes or more of data;

2. velocity: consisting of data created in real time or near to it; and

3. variety: consisting of structured or unstructured data, temporally and spatially referenced. Also, the data collected need to be fine grained in resolution and relational in nature; that is, capable of conjoining different types of data sets. They are also supposed to be flexible, meaning extendable and scalable at a later point (Kitchin 2014: 3).

\subsection{THE DATA-DRIVEN CITY}

Broadly speaking, there are two related interpretations of the data-driven city (Kitchin 2014: 1). The first vision pertains to a better management of the city from a largely technological and 
technocratic perspective and the second alludes to exploiting cities as information economies, wherein urban policies are directed mostly toward deploying digital infrastructures and services to boost digital entrepreneurship and the activities of the knowledge-based economy (Coletta et al. 2017).

As cities are revealing themselves to be the key sites for digital transformation and societal experimentation in the 21st century (Glaeser 2011, Offenhuber/Ratti 2014, Shelton et al. 2015), data is becoming both "the modus operandi and raison d'être" (Shelton et al. 2015: 16) of contemporary modes of urban governance. The real-time collection of large amounts of inexpensive data about urban activities and processes is also believed to enable new forms of adaptive management and digital modes of governance (see contribution 16 by Hamedinger in this volume). As mentioned earlier, the push toward a data-based understanding of the city is largely framed by economic and political narratives of an efficient, cost-effective, sustainable, competitive, productive, open, and transparent city (Kitchin 2014). It also entails the belief that a widescale, fine-grained, and real-time grasp of the city will lead to an enhanced "control of urbanity" (Kitchin 2014: 3).

According to Kitchin (2014), there are three main capture sources for urban data:

a. directed data: these are traditional forms of data collected through CCTV, fingerprints, iris scans, etc.;

b. automated data: these are collected from the measuring points of meteorological sensors, automated forms of surveillance, GPS, built-in sensors in road infrastructure, public transport systems, RFID chips attached to rubbish bins, etc.;

c. volunteered data: these are data "gifted" by users from their interactions across social media, such as Facebook and Twitter, or user-generated data in mobile devices contributing to a common system such as OpenStreetMap or the project EMOTIVE (see below).

The information-capturing notion of the IOT has further opened up vast application possibilities in virtually all technologically based processes in everyday life. The loT-based embedding of software (codes) into electronic gadgets of all kinds, transforms them from "dumb" to "smart" (Kitchin 2014: 4). Once the objects become smart, they are no longer independent entities but knots in global informational networks transmitting information that can subsequently be exploited for commercial use or for securitization achieved through various methods of surveillance.

As indicated above, an example of one of the most important applications of big data in the data-driven city is the securitization of public life with the help of sentiment analysis (Leszczynski 2016, Bassoo et al. 2017). Anticipatory security calculus designed to identify and divert risks of human behavior by using volunteered data combined with automated data is expected to deliver unprecedented ways of predicting of human behavior. A number of preemptive algorithmic calculi are being tested in different countries:

One experiment, called EMOTIVE - Extracting the Meaning of Terse Information in a Geo-Visualization of Emotion, is currently taking place in the UK. It is designed to monitor and map the emotional charge of online traffic and "shared atmospheres of affect" as expressed through individualized contributions to the social media platform Twitter (Leszczynski 2016: 1699). The aim of the project, as its website declares, is to predict and monitor selected events for the "benefit of social security" and to "safeguard the public from potentially harmful events" (EMOTIVE 2020). Subjected to such background analysis, the general public may legitimately question what checks and balances are in place to ensure that their private data is not being exploited and to determine and regularly reassess what is deemed "harmful" to whom, by whom. 
This technology, however, bears a considerable amount of risk, as it may exacerbate data expressing prejudices against social groups, places, and socio-spatial constellations. Additionally, the data will not be representative as normal situations will necessarily be underrepresented. Moreover, if a local government does have this information: What will it do with it? Hire more police? Enforce shutdowns during certain periods? Or declare a neighborhood as no-go area for tourists?

\subsection{THE COMPUTATIONAL UNDERSTANDING OF THE CITY AND ITS COMPLICATIONS}

The alluring promises of efficiency, safety and economic opportunities achieved through the use of big data and predictive analytics are increasingly leading to a computational understanding of the city (Shelton et al. 2015). This paradigm purports to comprehend urban phenomenon through a lens of digitalized data. It is inadvertently changing the culture and content of the urban debate that has evolved over the last hundred years around issues like public space, inequality, justice, public participation, etc. The explosion of digitized data and the role of cities as the main sites of their production, and the way these data are being used to reimagine the urban life of today and tomorrow, are moving to the center stage of the urbanism debate (Batty 2012, Townsend 2013). Cities embracing digitalization and ICT as their main development strategy have been labeled "wired cities," "cyber cities," "intelligent cities," "smart cities," etc. (Kitchin 2014). "Smart city" is undoubtedly the most popular term in use today-a term, and the prerogatives of which, academics have exhaustively critiqued, pointing to issues such as growing corporatization of city government, violation of privacy rights, cyberattacks, etc. (see Hollands 2008, Greenfield 2013, Townsend 2013, Kitchen 2014, Söderström et al. 2014).

At the core of the computational understanding of the city is the belief that all functions of a city can be measured and monitored, and all malfunctions can be treated as technical problems. Even complex social situations can be disassembled into neatly defined problems that can be solved, or at least optimized, through computation (Kitchin 2014). This position is based on a staunch belief in the linear and logical manageability of all societal and socio-spatial problems, a position that may prove to be deeply inadequate to tackle the challenges of the future, as shown by the arguments of a view known as "second modernity" or "reflexive modernization" (Beck et al. 1996). This view points out the ambivalent, risk-prone unpredictabilities and insecurities, marked by flows instead of structures, and sees connectivity both as a problem and as a project (see Dangschat in this volume).

Capturing especially the data of real-time phenomena has created the impression that it is possible to manage and fix a situation even while it is still unfolding. The computational understanding of the city is by no means new; its historic precursors go back to the "quantitative revolution" started by geographers and planners in the 1950s. Ever since, think tanks, corporations, and also academics have tried to tilt the discourse in urbanism from an ideographic and critical approach to a more rational, scientific, and depoliticized attitude (Hall 2002, Shelton et al. 2015). What has substantiated the ideas of the geographers of the 1950s, is the enormous improvement in the computational power of computer chips and technologies to efficiently capture and handle vast amounts of data.

The computational view of the world seems to be the resurrection of a 200-year-old idea sprung out of the then burgeoning discipline of classical mechanics. It was assumed that if Laplace's demon, a figure popularized in the early 19th-century sciences, knew the location and momentum of every atom in the universe, it could precisely predict the future of any given 
object in it. The technocratic view of the city implies, like Laplace's demon, that we can only understand its processes fully if we have enough data; and good governance is only possible if we subsequently employ an evidence-based, algorithmically processed mechanism that can process this data. This method alone is believed to ensure a rational, logical, and impartial decision-making process.

\subsection{REGULATING THE DATA-DRIVEN CITY}

Almost imperceptibly, data has ascended to become the most treasured resource and asset of the 21st century. While in the year 2000 there were three tech companies among the top ten most valuable corporations in the world, today, seven of them are data or tech companies-five American and two Chinese (Fengler/Gill 2019). The rise in the value of data and consequently in the power of those who possess them, has also brought the necessity to regulate them. This power and value have led to the flows and ownership of data becoming the most important subject of regulation-in addition, of course, to the long-existing flows of finance. Ongoing legal battles show how the regulation of data flows is still a globally fragmented endeavor (Aridi/ Petrovčič 2020).

This regulation is shaped by the views of two opposing groups: the anti-interventionists and the pro-interventionists (Bostoen 2018). The former argue that intervention in digital markets should be kept to a minimum, while the latter essentially believe meaningful principles for platform regulation must be put in place. However, both groups believe competition laws have to be rewritten, with diverging beliefs about how to apply the new rules and with varying strictness. Big political struggles are likely to be fought in the future around the regulation of data flows-something already concentrated in the hands of a small number of corporate titans.

The Regulatory Policy Division of the OECD (2019) and the ten principles proposed by the House of Lords in the UK (2019) point to some of the key issues and broad challenges concerning the development of frameworks and regulatory standards for this new world.

1. Transboundary challenge: Given the digital economy's clear cross-border effects, solutions limited to the domestic domain will no longer suffice; international regulatory cooperation is needed to avoid arbitrage, protect consumer rights, and promote interoperability across regulatory frameworks and enforcement, whilst creating a favorable environment for the digital economy to evolve.

2. Lack of knowledge: Most national legislatures are unaware of the socio-technical finesses of the evolving platform ecosystems. They are still based on pre-digital and pre-networked systems of governance. For example, "filter bubbles" or "personalization" are not part of the common legal discourse (Dijck et al. 2018: 157).

3. Problem of speed: Given the level of technical expertise involved, the uncertainty surrounding digital developments, and the overwhelming pace of digital transformation, governments need to actively engage a broad range of stakeholders, invest in foresight and horizon scanning, initiate regulatory impact assessments early in the policy-making process, and carry out post-implementation reviews.

4. A whole-of-government approach: This calls for increased dialogue and coherence between governmental bodies in order to meet institutional challenges and the cross-jurisdictional nature of the task. This may require the bringing together of key relevant players and the preparation of specific institutional responses by establishing thematic platforms. Governments also need to create a broader public debate by involving the civic sector. 
What further complicates the creation of broader regulatory frameworks for the data-driven city, is the simultaneous emergence and convergence of new technologies that revolve around big data, artificial intelligence, robotics, cloud computing, loT, 5G, along with new types of investment models (ITU 2020). It is becoming more and more evident that there cannot be a single framework of regulation: authorities have to perpetually navigate the complex and fast-moving digital landscapes of infrastructures, protocols, standards, and "user services" (House of Lords 2019: 11). Also, what makes regulation in liberal democracies particularly difficult at this critical juncture, is the need for strong political will to engrave democratic values into the underlying architecture of digital technologies and social practices.

Regulating the digital world is a gargantuan task that will need the involvement of many countries, actors, and negotiations on many different levels. Some observers in Europe say new regulatory authorities should be designed at the EU level (OECD 2019), while others say it would be more fruitful if national authorities simply collaborated more intensely. A number of national and international organizations, such as the UN-based International Telecommunication Union (ITU 2020), the Regulatory Policy Division of the OECD (2019), the Digital Charter of the UK (Digital Charter 2018), and Canada's Directive on Regulation, are in fact coming together to work on the topic in more concerted ways. How to safeguard citizens and institutions in the data-driven world without hampering innovation and competition, has become the key challenge for regulators. It is becoming evident that it will not be about more regulation but about a different approach to regulation (see section 3.3).

\subsection{GOVERNANCE: EXAMPLES OF ALTERNATIVE APPROACHES}

Another critical question that arises in view of the immense influence of the data-driven city and the computational understanding of the urban is: how is it impacting the mindset of planners, administrators, politicians, and citizens? If we say regulation is about controlling digital transformation, and governance is about finding consensus on socially shared visions for the future of people and places reached through complicated negotiation processes between the state, market, and civil society, then it is evident that we must find new participatory processes of enforcement of regulations in the cyber-physical city.

Besides an overriding number of examples of the digitized city being technocratically and entrepreneurially exploited, we also see an increasing number of alternative approaches (Townsend 2013, Banerjee 2014, Banerjee/Fischer-Schreiber 2015). For example, in the conceptualizations of the cyber-physical city based on "open data", we see some promising prospects of democratic and inclusive development. This is a movement fighting to make big data a public prerogative and a common good. Many governments around the world have started to release various kinds of administrative and operational data using various kinds of open-data models (Ferro/Osella 2013, Leszczynski 2016). For example, the city of Santander in Spain created the app SmartSantanderRA to provide real-time information to citizens about around 2,700 places, such as libraries, public buses, bike rental services, etc. Together with the City of London, University College London (UCL) has developed London Dashboard, a data visualization app that tracks the city's performance in twelve areas, such as jobs, transport, etc. It communicates to citizens live feeds of real-time data. Another example is Dublinked in Dublin; this platform provides operational data from four authorities in Dublin in an open format, encouraging the creation of apps providing services of social value by using these data. The increasing number of such examples shows how different the practices of producing the data-driven city can be-owing to the initiatives of single actors or to locally specific conditions of culture, politics, or governance. They also show that such progressive local initiatives can take place even within prevailing conservative ideologies. 


\section{DIGITAL PLATFORMS}

\subsection{RISE OF THE PLATFORM SOCIETY}

This section looks at how data-based "transactional technologies" are becoming essential constituents of the data-driven city and how the challenge of regulating them is becoming the key question of shaping cities and society at large.

The idea of matching supply and demand by creatively processing of torrents of digitized data has led to the rise of one of the most disruptive socio-technical formations of the $21 \mathrm{st}$ century: the digital platform. Knowingly or unknowingly, digital platforms have become integral parts of our everyday lives. We make use of them through connectivity services offered by social media giants such as Facebook, mobility services by tech start-ups such as Uber, accomodation renting through Airbnb, educational services by Coursera, health services by PatientsLikeMe, rating apps like Tripadvisor, etc. Digital platforms position themselves as key intermediaries in the provision of services in all domains of society. Almost imperceptibly, they are reorganizing and reconfiguring communication, entertainment, mobility, travel, work, government, and increasingly politics, by gradually embedding themselves in everyday human life.

Even though the term "digital platform," or simply "platform," is widely used by public authorities and the media, a workable definition for it is lacking. In a seminal publication on the "platform society," Van Dijk, Poell, and de Waal (2018) define digital platforms broadly as a "programmable digital architecture designed to organize interactions between users-not just end users but also corporate entities and public bodies. It is geared towards the systematic collection, algorithmic processing, circulation and monetization of user data" (Dijck et al. 2018: 4). From a more market-centered viewpoint, the European Commission defines them as "an undertaking operating in two (or multi)-sided markets, which uses the internet to enable interactions between two or more distinct but interdependent groups of users so as to generate value for at least one of the groups" (European Commission 2015). Platforms can take the shape of search engines, marketplaces, social media platforms, gaming platforms, content-sharing platforms, etc. An important delineation to be drawn between platforms is that some are designed to be essentially collaborative and not-for-profit and some operate with overt commercial interest (Stowel/Vergote 2016). Even though both rely on matching supply and demand, and both use technology to reduce transaction costs for their users, there are differences in their internal logic. There is a difference, for example, between wanting to enable modest sharing of, say, harvests from private gardens with neighbors or knowledge within a scientific community, and wanting to conquer global markets with the backing of billions of dollars of venture capital.

It is becoming more and more evident that online platforms are pervading all sectors of private and public life and transforming the fundamental organizational structures of society. The term "platform society" denotes the inextricable relationship growing between such online platforms, societal structures, and individual behavior. They are increasingly "penetrating the heart of societies-affecting institutions, economic transactions, and social and cultural practices [...]" (Dijk et al. 2018: 2). Automated forms of user transactions are replacing a growing number of offline organizations, as demonstrated, for example, in Estonia's much-acclaimed showpiece, the public sector platform e-Estonia (Priisalu/Ottis 2017), or in the United Kingdom's push toward creating a "government-as-a-platform" (Dijk et al. 2018). These examples show how far the platform's impact has penetrated the domain of government. 
It is astonishing to see how a very small number of players could constitute the epicenter of the "platform revolution" (Parket et al. 2016). Located on the West Coast of the USA, merely five tech companies from the region-Alphabet/Google, Facebook, Apple, Amazon, and Microsofthave captured the digital spaces of the whole of North America, Europe, and large parts of Asia and Australia. The only other country to have developed platforms of a comparable scale is China, with Tencent and Baidu. While the "Big Five" dominate the global market, there is a rapidly growing number of small actors shaping the local universes of platforms. Governments, businesses, entrepreneurs, universities, NGOs, cooperatives: all are contributing to producing a new, highly complex, interconnected landscape of platform practices.

\subsection{FROM "SMART URBANISM" TO "PLATFORM URBANISM"}

Even though the boundary between the (ill-defined) concepts of smart urbanism and platform urbanism is fuzzy, Söderström and Mermet (2020) have recently identified three features that distinguish platform urbanism from smart urbanism. They relate to the former's (a) materiality, (b) impact on everyday life, and (c) actual effect on how cities work and change. Materiality pertains to how platform processes are manifested in things like Uber cars or Airbnb rooms. This differs significantly from how surveillance cameras and sensors create impressive "smart city control rooms," such as the often-cited and illustrated room built by IBM in Rio de Janeiro. Sarah Barns (2018) makes the following remark about the second difference: "[p]latform urbanism enacted daily as we commute, transact, love, post, listen, tweet or chat, deeply implicates the everyday urban encounter" (Barns 2018: 6).

While smart urbanism is associated with extracting data, such as measuring, tracking, and tracing people, platform urbanism is interactive, intimate, and deeply engaged with everyday life. For these platforms, we gladly volunteer to "like" places, foods, or hotels. While the smart city remains somewhat shrouded in techno-utopian or dystopian imagery, platform urbanism conveys tangible, intimate, and everyday experiences of the city through its technology. Concerning the third difference, Leszczynski (2020) says that while smart city projects address municipalities, private companies, or sometimes civil society, digital platforms directly target individual customers and "by reaching into the pockets of urbanites, [they] express a potential for individualized influence unprecedented by 'smart' infrastructure-urban configurations" (Leszczynski 2020: 5). She further says that platform urbanism should be considered a "reconfiguration, diversification and intensification" or "extension" of the smart city (Leszczynski 2020: 5).

These three differences may very well be the reason for the remarkable success of the sectoral platforms that offer services via apps (see 3.2.2). For example, in 2014, Apple's infrastructure platform iOS had 365 million users who downloaded 800,000 complementary apps, created by 200,000 firms-a process over which Apple has little ownership (Tiwana 2014). From 192 billion in 2018, the total number of app downloads increased to 204 billion in 2019 (Clement 2020). Almost unnoticed, these small waves of millions of digital apps are forming a giant tsunami of services, ready to crash onto the shores of the contemporary physical city in unprecedented ways.

\subsection{THE PROBLEM OF PLATFORMS AND THE CHALLENGE OF THEIR REGULATION}

Admittedly, platforms have greatly improved many of our lives in various ways. However, while modest and peer-to-peer platforms hardly cause disapproval, the practices of commercially operating corporate giants have generated considerable public outcry and calls for appropri- 
ate regulation for their elusive practices. Despite the very high degree of user acceptance, intrinsic flaws in the mechanisms of commercially operating global platforms have led to various confrontations between private and public interests-which have subsequently triggered a substantial debate around the question of how to regulate these new types of entities. Legal battles and backlashes against big tech companies culminated in 2017, making it a turning point for global platform politics. For example, Alphabet/YouTube faced a strike from major advertisers like The Guardian, Starbucks, and Walmart; Alphabet was fined US $\$ 2.7$ billion by European antitrust officials; German competition authorities took Facebook to court for their incomprehensible consumer agreements; the European Court ruled Uber to be a "transportation company" and not the "connective platform" of a "tech company"; and Equifax reported that they had lost 136 million social security numbers to thieves in the digital space. This was a year before the EU member states adopted the General Data Protection Regulation (GDPR), a novel attempt to protect personal data, albeit not specifically for the digital space.

There are three general ways in which regulation of the cyber-physical world is enforced (House of Lords 2019): (a) "regulation," (b) "co-regulation," and (c) "self-regulation." "Regulation" is about enforcing rules for specific types of activities. This is carried out by independent bodies with the power to monitor and enforce rules. "Co-regulation" takes place when digital enterprises set rules by themselves on a voluntary basis. This may be driven by the need to create trust, by corporate social responsibility, or by other business interests. "Self-regulation" occurs when a regulatory body delegates responsibility for enforcing rules to an industry body. To understand the challenge of regulating digital platforms in a specific way, it is helpful to understand an interconnected range of issues stemming largely from three of their foundational features: their legal engineering, their disruptive business models, and the technological finesses of their digital architecture.

\subsubsection{Legal engineering and disruptive business models}

Researchers have shown that the so-called platform revolution (Parker et al. 2016) was made possible largely by the platforms' capacity to accumulate vast amounts of personal data, create unprecedented degrees of connectivity, and generate economic value below the radar of existing regulatory institutions (Dijk et al. 2018). The success of platforms is based on the premise that "they offer personalized services and contribute to innovation and economic growth, while efficiently bypassing incumbent organizations, cumbersome regulations, and unnecessary expenses" (Dijk et al. 2018: 9). This legal engineering is not merely accidental-it is believed to be the core of platforms' success: "Digital platforms obviously challenge the law, and this is a key feature and consequence of their operations. They like to show how the law is out-of-date with the new economy, and they even appear alien to the law. Indeed, they tend to negate the territorial aspect of the (State) law" (Stowel/Vergote 2016: 4).

For these sophisticated operators harboring global ambitions with monopolistic tendencies, rules applicable on national territory appear an anachronism in the digital age, which poses the challenges of "reflexive modernization," where government is no longer limited to state boundaries but has to develop cross-border governance across scales (Brenner 1998, 2019). This conjuncture has led to intensifying tensions of a geopolitical nature between governments, corporations, and civil society. Considering the differences in how the market and jurisdiction are viewed on either side of the Atlantic is crucial when designing competition policies for platforms. The discourse in the US is far from any form of consensus: While former presidential candidate Elizabeth Warren is talking about ways to break up the monopolistic power of tech giants, others are suggesting some of the existing antitrust doctrines should be relaxed. Like the European Union, the US courts are also looking for new ways to address the anticompetitive practices of the tech giants. 
Globally operating platforms are fueled by data, organized through algorithms, formalized through ownership relations, driven by business models, and governed through user agreements (Dijk et al. 2018: 9). To understand the premises upon which the foundations of the corporate platforms' techno-legal and techno-commercial strategies are built, it is necessary to examine the functional building blocks of their digital architecture (structures) and their mechanisms of processing data and performing transactions (processes).

\subsubsection{Digital architecture: Source of techno-legal fuzziness}

Much of the elusiveness of online platforms' operations stems from the intricate digital architecture of platforms defined mainly by: (1) algorithms, (2) infrastructural platforms, (3) sectoral platforms, and (4) ecosystems of platforms.

1. Algorithms: Algorithms are an essential technological ingredient comprising a set of automated instructions that transform input data into a desired output. They have the capacity to produce, reproduce, and learn. Platform operators are currently moving from rule-based algorithms to machine learning-based algorithms driven by $\mathrm{Al}$; this makes decision processes even more opaque for regulators to understand.

2. Infrastructural platforms: Van Dijk et al. (2018) distinguish two principle types of platform architecture: infrastructural and sectoral. The infrastructural platforms, mostly owned by the Big Five, are the foundational platforms upon which other platforms can be built. Like gatekeepers, they manage, process, store, and channel the data that flows through them. They can be search engines, browsers, data services, data analytics services, video hosting platforms (like YouTube), geospatial services (like Google Maps), etc. For example, Netflix runs on the infrastructural platform Amazon Web Services, Spotify on Google Cloud (Dijk et al. 2018). They form the heart of the "ecosystem of platforms."

3. Sectoral platforms: The second type of platforms are called sectoral platforms. These platforms serve particular sectors, such as transportation, news, education, food, health, finance, hospitality, etc. They can be owned by diverse organizations. Two well-known sectoral platforms are Airbnb and Uber. Both have claimed to be merely "connective platforms," that is, connecting dormant resources and people. The innumerable applications running on these sectoral platforms are popularly called "apps" (see fig. 1 and section 3.2). Potential platforms for CAVs will be built on such sectoral platforms.

4. Ecosystems of platforms: What has made platforms so powerful is the technological innovation of application programming interfaces (APIs). With the help of APIs, platforms can allow controlled access to their data by third parties-information on which they can build new applications (Helmond 2015). This important ingredient of interlocking functionality created the possibility of establishing large "ecosystems of platforms." For example, Google's search and advertising services can be coupled to its educational platforms; Facebook can produce news content, etc. They are also described as "assemblages of networked platforms" (Stowel/Vergote 2016, Dijk et al. 2018, House of Lords 2019). An important feature of these assemblages is that they enable corporate platforms to partner with a wide variety of non-profit and public players. The Western assemblage of networked platforms and their infrastructural services are almost entirely controlled by the Big Five in the USA. They are central to the ecosystems' overall design and data flow distribution. The exchange of information, goods, and services with global outreach would be unthinkable without these platforms. 
Figure 2: Schematic diagram of the ecosystem of digital platforms. New values (services) are created by allowing sectoral digital platforms to build upon each other through the interlocking functionality of application programming interfaces (APIs).

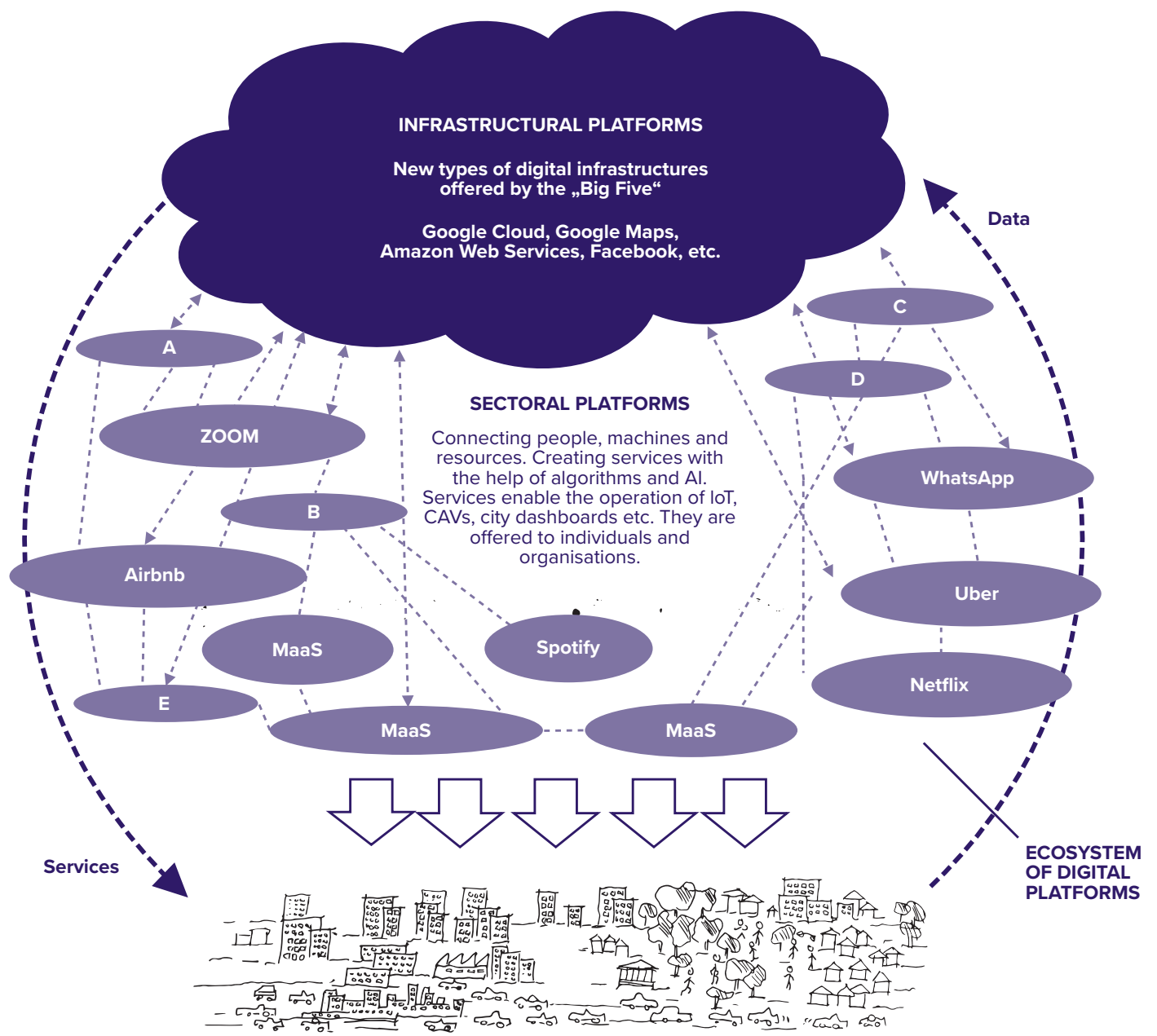

Scource: Ian Banerjee

These four above-mentioned aspects explain a major part of the fuzziness that makes regulation so problematic. In a way, it can be seen as a fuzziness of identity. Most regulation systems in Europe depend on the division between infrastructure and sectors. Correspondingly, the task of regulating online platforms is traditionally compartmentalized, meaning each level of government assumes a limited range of regulatory categories. To avoid the costs of liabilities and responsibilities, platforms blur or deliberately obfuscate these categories. Airbnb does not identify itself as a hotel business, and Uber does not consider itself a taxi business; instead, both see themselves as connectivity platforms. In the case of Uber, their legal battle with legacy taxi firms revolves around the indistinction regarding whether Uber is a sectoral platform (a transportation company) or a platform that merely connects people. When data flows cannot be confined to one single sector, such as transport or health, then platform providers can evade national legislations and "elude the radars of public scrutiny" (Dijk et al. 2018: 158). This conflict was at the heart of the European court case mentioned above until the European Court of Justice finally ruled Uber to be a transportation company (Dijk et al. 2018).

Governments will have to understand these mechanisms and immaterial dynamics of the ecosystem of platforms in order to define the material responsibilities of their online services. 
Airbnb can help individuals to make some extra money and tourists to pay less-but who is going to clean the streets when the tourists have left? Students can consume "free" courses on Coursera-but who pays the teachers who prepared the courses? The economic success of all these platforms depends on private and public investments, largely paid for by taxation, i.e., transportation relies on infrastructure like highways and railroads, as well as maintenance and cleaning companies. Without those hard infrastructures, neither Uber nor Airbnb will work. This argument lies at the heart of the current legal contentions.

\subsubsection{Mechanisms of transactions: Source of socio-technical conflicts}

Platforms are not merely connectors between actors, they can also steer how they connect users with each other-and they can also shape social norms. Through a number of social plugins, such as the "like" button, or through rating, following, sharing, etc., sentiments, interests, and opinions can be tracked and tilted by platforms in certain directions: steering users' behavior, and potentially paving the way for new economic exchanges.

The mechanisms of processing data and conducting transactions are embedded in the architecture of platforms and are comparable to the "genes" of their structures: they carry their system's codes of reproduction. To design governance models for platforms, it is essential to understand the conflicts arising from the effects of these mechanisms. Van Dijk et al. (2018) have identified three of them as the main forces shaping the dynamics of the ecosystem; they are: (1) datafication, (2) selection, and (3) commodification.

1. Datafication is about collecting vast amounts of user data and subsequently aggregating, disaggregating, unbundling, and rebundling them into digital products. Datafication is potentially an excellent means to contribute to the general well-being. It can improve traffic management, solve health problems, etc. The availability and accessibility of (real-time) data shared through open standards could contribute greatly to societal benefits. Aggregated data sets may not only hold economic value but also public value. However, datafication has become one of the most contested issues in the field. Its vastness and complexity have been made possible by the tech giants' holy grail of high technology. The problem lies in the fact that these operators usually capture, store, and resell data without compensating the public. This monetization takes place well outside the reach of regulators, and users usually lose control over their data after having accepted the platform's terms of service-hereafter, they become a proprietary asset. The movement of such large amounts of data (enabled by a handful of companies) makes it almost impossible to trace them and therefore there is little public accountability. How to make data traceable, their flows transparent, and bestow users with a better sense of ownership, are at the heart of the legal discourse around platforms.

2. Selection involves the mechanisms of filtering, ranking, and personalization of data. Again, it is not intrinsically faulty; personalized health care, for example, can be very beneficial; but the very same mechanism can become detrimental for citizens if breaches in privacy lead to high rates for insurance for i.e., disabled persons.

3. Commodification is a mechanism that transforms data into economic value. In simple terms, this mechanism connects producers to customers, and importantly, advertisers to content. A myriad of monetization schemes shapes the "notoriously untransparent" practices of commodification (Dijk et al. 2018: 144). What complicates this simple mechanism is that corporate platforms often partner with non-profit and public players, and in so doing "render fluid the distinction between for-profit and non-profit, private and public, free and paid for, infrastructural and sectoral, complementors and connectors-and between global, national 
and local markets" (Dijk et al. 2018: 144). The accountability discussion raises the question of governance: Who is accountable to whom? Who has ownership over what (Annany/Crawford 2016)? However, even here, commodification could in principle also create public values, though the ubiquitous public value-based design of platforms is still a far-fetched ideal.

In all mechanisms we see the repeated need for new taxonomies of governance or regulation that will make transactions more transparent and accountable. Essential for the governance of these mechanisms is to rethink the principles according to which these socio-technical systems are designed. It requires clarity about the values needed to inform the online systems (see section 3.4).

\subsubsection{Possible approaches to regulation: Rules-based or principles-based?}

All socio-economic activities take place within certain regulatory frameworks. These new types of commercial operators have exploited a momentary regulatory gap, which is currently being closed. The two main approaches to regulation are rules-based or principles-based (Stowel/Vergote 2016, Dijk et al. 2018, House of Lords 2019). Principles-based regulation focuses on outcomes, whereas rules-based regulation prescribes the format of compliance (House of Lords 2019: 14). An example of the latter are the data protection principles that underlie the General Data Protection Regulation (GDPR). These principles subsequently led to the GDPR's guidelines, codes of practice, and certification: a principles-based approach can help to establish a common understanding for addressing issues that cut across sectors and can provide a common framework for regulators, executive bodies, policy-makers, and lawmakers (House of Lords 2019: 14). Also, the rapid pace of technological development makes a principles-based approach seem more appropriate, because it creates a certain flexibility by setting out the standards and expectations of service providers.

A general principle that is gaining interest is the outcome-oriented principle of "public value" (for more, see 5.2). The House of Lords (2019) has broken down the general public value-centric approach into ten subgroups: (1) parity of equivalent outcomes online and offline, (2) accountability, (3) transparency, (4) openness, (5) ethical design, (6) privacy, (7) recognition of childhood, (8) respect for human rights and equality rights, (9) education and awareness-raising, and (10) democratic accountability, proportionality, and an evidence-based approach (for more, see House of Lords 2019: 15). The aim of working with these principles is to help the industry, regulators, government, and users work toward a common goal of making the internet a better environment that is beneficial to all.

A crucial topic for the governance of the platform society is the challenge of the digital divide. There are three main issues here. Firstly, concerning infrastructure, the world is far from having ubiquitous presence of the internet-even in highly industrialized countries many peripheral areas are still undersupplied. Secondly, concerning individuals, not only is the question of purchasing devices to use Web 2.0 relevant, but so too are the competencies needed to maneuver in the cyber-physical space. When this fact is mentioned, if at all, it is usually labeled as the problem of the elderly, which it is therefore self-evidently assumed will fade away over time. This approach is to be questioned, as the progress in technological transformation, particularly in communication, is so rapid and complex that even the "digital natives" will sooner or later struggle to keep up with the speed of change and themselves turn into "digital immigrants." Thirdly, the different use of the digital world does not depend on age or gender but on social position. The digital divide results on the one hand in the intensification of existing social inequalities and on the other in the creation of new forms of inequality-in extreme cases it leads to groups' exclusion from digital societies (Rudolph 2019). This may happen with growing frequency, particularly if daily life is increasingly organized via apps (e.g., for access to mobility). 


\subsection{DIGITAL TRANSPORT PLATFORMS}

\subsubsection{Datafied marketplaces, pricing, and trust}

From the perspective of digital platforms, urban transport platforms can be seen as datafied marketplaces (Dijk et al. 2018), where data extracted from various infrastructural and personal sources are matched with specific mechanisms to meet demand with supply, while lowering transactional costs (Dijk et al. 2018). Datafied marketplaces are increasingly being created by both the private and public sector-leading to the convergence of all modes of transport (see section 4 on MaaS). However, the playing field is far from equal, as the amounts of data owned by tech companies vastly outweigh the data streams collected or owned by the public sector. The unwillingness to share their data may lead to a potential conflict of interest between commercial operators and the common good of a well-functioning, integrated transit system.

Two important aspects of the datafied marketplace of digital transport platforms are pricing and the organization of trust. Pricing plays a central role in the transport business; however, it remains unclear whose interests are served: Is it to increase net gain for the platform? Is it to optimize travel and waiting times for all passengers? Or is it to optimize travel for premium customers at the cost of other groups (Dijk et al. 2018: 81)? Trust is another key element for the success of transport platforms. Platforms vitally need trust and a good reputation to operate: an increasing number of users want platforms to assume more responsibility. Normative rating apparatuses used by companies like Uber are well known. For CAVs, the trust systems will have to be engineered in different ways, for example by showing the degree of geographic coverage of a transport network company (TNC), or maybe how well they are serving structurally underserved areas.

\subsubsection{Governance: An example of an alternative approach}

As many scholars have often pointed out, sharing models (including those for CAVs) will not automatically make transit systems more efficient for all social groups. In fact, the opposite will be the case if it is not governed with a comprehensive view. For example, ride-sharing services in New York have led to a fall in ridership of the metro since their introduction in 2016; consequently, the average speed in central Manhattan fell by 12\% from 2010 to 8.1 miles per hour in 2017 (Fitzsimmons/Hu 2017).

\section{Case study: São Paulo-Government as the central actor}

An interesting example of designing a comprehensive approach toward platformization of an entire urban transportation system can be witnessed in the megacity of São Paulo-a city notorious for being segregated with starkly unequal access to services. The city management of São Paulo is currently recalibrating the commodification of the urban mobility system and testing a novel transport concept. In a new proposed law, the local government will sell "credits" to all network service providers that want to make use of the city's infrastructure. For each kilometer driven, a TNC will have to buy mobility credits, which will be auctioned off on a payas-you-drive model. These credits will be priced dynamically; for example, they will be made cheaper for providers offering public transport to the underserved, or for providing transport for disabled persons, to stimulate providers to serve a particular group of customers. They will also be used to promote certain labor market policies-for example, by reserving a certain amount of credits for female drivers.

This case study shows how public values can be incorporated into the conceptualization of a platform's mechanism of commodification. The goal is to maximize the transport system's effi- 
ciency from the point of view of public values rather than profit alone (Dijk et al. 2018). Findings from this large-scale experiment could be valuable for the widescale deployment of CAVs in the future.

\section{THE CASE OF MAAS: PLANNING IN TIMES OF DEEP UNCERTAINTY}

\subsection{MAAS: BENEFITS AND CHALLENGES}

Digitalization in the transport sector has brought about substantial changes to the incumbent transport industry. In particular, the way digital platforms are applied have significantly revolutionized mobility services: they provide new channels for travelers and service providers to interact and enable new business models and mobility services to emerge. Consequentially, the urban transport system landscape in cities around the world is transforming in ways that were unimaginable even a decade ago.

At the center of this development is a new transport concept called "Mobility-as-a-Service" (MaaS). MaaS is a transport concept that combines different transport services to provide travelers with a transport solution via a single interface. The available transport services are bundled together and offered to users in exchange for a monthly payment or a pay-as-you-go tariff, similar to mobile phone services. It provides a demand-orientated mobility service that can be tailored and customized to meet users' requirements (for reviews of MaaS, see Kamargianni et al. 2016, Jittrapirom et al. 2017, Pangbourne et al. 2018).

Arguably, the concept of providing mobility as a service even predates the automobile. With horse-drawn carriages, taxis, vehicle renting and sharing services, travelers could already access and benefit from these modes of transport without having to own them. Also, efforts to bring together different modes of transport by amalgamating vehicles, schedules, and payment under the notion of integrated transport has been ongoing for decades. Smart mobility concepts, which aim to implement the loT in the transport system to enhance convenience, accessibility, and better management of individual mobility services are already prevalent and have become part of daily life in several cities. So, what is new and unique about MaaS?

The novelties that set it apart are twofold. Firstly, the principal focus of MaaS is in meeting travelers' needs. MaaS seeks to combine existing advanced technologies to provide a layer of information exchange that can seamlessly integrate these different modes of transport to provide a mobility service that caters to users' needs (Finger et al. 2015). This focus is more explicit in MaaS than in the other previous transport concepts. In MaaS, each traveler is theoretically offered a range of mobility options, which are selected and optimized by a computer algorithm to best fit their needs. The provision of a single platform that combines all available modes will also ease accessibility and call attention to less familiar or new modes, as well as the interchangeability between different modes.

Secondly, MaaS can bring together the positive attributes and characteristics of existing mobility concepts (e.g., sustainable, active, and integrated mobility) to better manage the overall operation of urban transport systems (Wong et al. 2019). For instance, MaaS can contribute to the better use of the available capacity by enabling supply and demand to match better, and allowing travelers to switch spontaneously from, say, congested systems of transport to those with more available capacity. Also, MaaS can deter travelers from private vehicle use with its "access instead of ownership" paradigm, and potentially offer sustainable and seamless mobility services. 
These innovations can combine to offer an effective solution to address localized urban transport challenges (e.g., congestion, air quality, noise) and respond to the global challenge of the climate emergency. MaaS can also offer several short-term perks (e.g., convenience, health benefits, and other incentives) required to encourage travelers to use a more sustainable and environmentally friendly mode through its personalization and integration with other sectors (e.g., retail).

Despite the many potential benefits, there are a number of challenging issues around the planning of MaaS. For example, it is still questionable whether the aforementioned perks are sufficient to alter travelers' behavior or whether it would need additional infrastructure to induce change-as the choice of mode is often argued to be rooted "in the human physiological structure" (Knoflacher 2007: 395). Moreover, "MaaS has considerable potential for deception" (Pangbourne et al. 2019: 13), as the narratives around MaaS are largely dominated by private businesses that usually see it solely as a means to achieve higher levels of efficiency and convenience in the transport sector. While these arguments may hold, efforts must be made to bring about a more balanced discussion that examines other aspects, such as equity, sustainability, and environmental impacts.

The role of the public sector will be absolutely crucial in ensuring the involvement of other stakeholders, (such as the civic sector) and in realizing the societal benefits associated with Mobility as a Service (Jittrapirom et al. 2018b). Although several public sector activities have been ongoing for a decade (see box 1 below), more can be done to help the public to understand MaaS and encourage them to engage with the discourses that are currently still limited to tech companies, public service providers, academia, and governmental organizations. The limited public involvement may stem from the novelty of MaaS as a concept; however, only a broader engagement of citizens can turn MaaS into a valuable constituent of future urban landscapes.

\subsection{PILOT PROJECTS AND SCHEMES OF MAAS: GOVERNMENT AS A CENTRAL ACTOR}

The potential prospects of MaaS in solving urban transport problems have attracted the interest of public policymakers from around the world. The European Commission, for example, has been very active in stimulating activities associated with MaaS (see box 1). At the member state level-particularly in the Austria, Finland, Netherlands, Finland and UK - there are lively discussions and initiatives around MaaS (Polis 2017).

Box 1: A selection of activities related to MaaS with government as the central actor.

The European Commission had declared 2018 to be the "Year of Multimodality" to emphasize the importance of multimodality for EU transport systems and dedicated three key thematic areas to MaaS: digitalization, support for multimodal (physical and digital) infrastructure and innovation, and legislative framework to protect passenger rights during multimodal journeys. The Commission also started to provide funding in 2018 to support the advancement of MaaS through several financial mechanisms, such as Horizon 2020, Multiannual Financial Framework (MFF), and the new Framework Programme for Research and Innovation (FP9). Additionally, it also organized Digital Transport Days and the Transport Cybersecurity Conference for the first time in 2019. 
In the Netherlands, MaaS has attracted keen interest from various parties. It is seen as a stepping-stone toward building a sustainable and smart city, strongly driven by the promise of efficiency gained through new transport systems and the potential to create new business opportunities. In 2016 the MaaSifest taskforce was established, bringing together experts from various sectors to formulate action plans to accelerate the adoption of MaaS (MaaSifest n.d.). The Dutch central government and the Ministry for Infrastructure and Water Management have also shown interest in MaaS as an alternative approach to solving transport congestion alongside investment in infrastructure and public transportation. Several initiatives have been launched to support this ambition and to accelerate its realization. They include the implementation of projects, such as SCRIPTS in 2016 and the initiation of market consultations on MaaS in 2017. A tendering process in 2018 followed the latter for pilot projects in seven regions - Amsterdam, Eindhoven, Limburg, Northern provinces, Rotterdam, Twente and Utrecht - several of these pilots are underway as of 2020 .

In Finland the active governmental support for MaaS is led by the Finnish Transport Agency, which published a report on MaaS in 2015. In 2016 the Helsinki Regional Transport Authority (HSL) agreed on a cooperation with Whim, a MaaS platform, to sell its single-journey ticket through its platform (HSL 2016). This agreement was the first of its kind in a real-world operational setting. The following year, the Finish government published a new act on transport services, with the aim of creating the preconditions for the digitalization of transport services and new business models. The act consists of three components: (1) the provision on the interoperability of data and information systems (came into force on January 1, 2018); (2) provisions for air, maritime, and rail markets and the opening up of data and regulation of transport registers; and (3) a reflection on the act's objectives of creating digital services. This act was adopted as of July 1, 2018 (Vayla 2018).

The government of the United Kingdom, headed by the Department of Transport, commissioned a study on MaaS to examine its feasibility for London in 2015 (Kamargianni et al. 2015). The study found that the application of MaaS would bring potential benefits to transport operators, and that it would outweigh the potential costs. Subsequently, the government called for a roundtable discussion on MaaS in 2017 (Governement Office for Science 2017) and thereafter launched a formal inquiry into the subject (Parliament 2017). Currently, there are several MaaS research projects running in the UK (e.g., MaaS4EU and Pro-MaaS by MaaS Lab). This also includes the operation of the Whim service (see Finland) in the Midlands region of the UK.

In Japan, the Ministry of Land, Infrastructure, Transport, and Tourism (MLIT) and the Ministry of Economy, Trade, and Industry (METI) launched a Smart Mobility Challenge Promotion council in 2019. The commission brought together local authorities, private business, and other related institutions to discuss the potentials and opportunities of new mobility services in Japan. Later that year, the council called for a public tender and selected 19 advanced MaaS pilot projects with a total value of $¥ 3.1$ billion (approx. $€ 25$ million). The 19 projects can be classified into MaaS for suburban, rural, and depopulated areas, and also for tourism. Several of them have been in operation since late 2019 and are expected to continue till the end of 2020 . 


\subsection{PLANNING MAAS DURING DEEP UNCERTAINTY}

The pilot projects conducted in different countries have provided the first indications of the necessary preconditions for implementing MaaS on a large scale, as well as the quantification of possible impacts of MaaS on the performance of the transport system in general. However, these indications are still too limited in number and often too case-specific to allow broad generalizations. There is still a high degree of uncertainty surrounding MaaS as to how it should be implemented, and what the real benefits would be from its large-scale rollout (Jittrapirom et al. 2018a).

The level of uncertainty is high for several reasons. Firstly, knowledge about this novel transport concept is still limited. Several of the issues shaping the ongoing debate revolve around the ambiguities underlying the precise definition of the service, its overall effect on the urban transport system, and the uncertainties regarding users' and stakeholders' acceptance. The second dimension concerns the complexity of the urban transport system, which stems from the interconnectivity and interoperability of the entities within the urban system (Kölbl et al. 2008). The complex entanglements between these different entities make it difficult to predict future behaviors resulting from any single intervention (Pojani/Stead 2015, Jittrapirom et al. 2017). Thirdly, the evaluation of the outcome of interventions by decision makers can be uncertain. Although these outcomes may be forecasted with some certainty, the inherent subjectivity of their evaluation can be influenced by contingent factors, such as public mood at the time of measurement. Finally, uncertainties associated with external forces play a significant role. Specific forces, such as demographic development, can be forecasted with some accuracy using past data, whereas other forces, such as national economic development or other surprise events (i.e., a black swan), are more difficult to predict. Researchers are addressing these uncertainties by adapting appropriate planning techniques, for instance, robust decision-making (RDM) and Dynamic Adaptive Policy Pathways (DAPP; see Haasnoot et al. 2019, Lempert 2019, Walker et al. 2019).

\section{Dynamic Adaptive Policy Pathways}

A promising alternative to the orthodox planning technique that has been suggested in view of developing MaaS is Dynamic Adaptive Policymaking (DAP), which deals with uncertainties by assuming that they can be predicted with some accuracy using statistical or scenario-based approaches. The DAP approach first allows policies to be developed for novel concepts using available information and then focuses on reducing uncertainties during their implementation through monitoring and adaptation processes. It helps policy makers to deal with deep uncertainties regarding contested opinions and mental models of those involved in the planning process when those policy makers have no previous experience to draw upon (see Jittrapirom et al. 2018a for how DAP is applied to MaaS planning). However, there are several drawbacks of DAP. As a "predict and act" method, it is based on explorations of past experiences that may be limited in dealing with the implementation of MaaS. For instance, its development process often involves a limited group of experts, potentially restricting the perspectives and the comprehensiveness of the plan. Also, there are challenges in implementing the approach in practice, which includes dealing with complex and contested issues and establishing the trigger points for the complex system. Moreover, it needs to take into account the implications of institutions and governance (Bosomworth et al. 2017). Finally, DAP requires additional techniques to calculate the costs involved in shifting between different plans of the adaptive pathways (Haasnoot et al. 2019). Some studies have sought to address these weaknesses by combining DAP with computational simulation (Hamarat et al. 2013) and some by involving groups of different experts (Pas et al. 2012). Yet another study combines DAP with the Delphi method, an anonymized way to systematically capture the opinion of a group of experts (Jittrapirom et al. 2018b). 


\section{WHAT DOES THIS MEAN FOR CAVS?}

\subsection{COMPREHENSIVE PLANNING}

As researchers have repeatedly pointed out, if unregulated, CAVs and other new mobility solutions-such as car-sharing, ride-sharing, and ride-hailing services-are expected to make cars even more appealing and hence possibly draw passengers away from (existing) public transport systems (EU Science Hub 2019). Therefore, how to design a comprehensive transport system will remain the key challenge for mobility management. If a country or a city administration is willing to deploy CAVs while simultaneously subscribing to progressive policies of making transport cleaner and more equitable than its car-centered present, then it will have to engage with research and the political questions of planning that address questions revolving around (a) how to minimize the risks of implementing new mobility services by instigating dynamic forms of adaptive policymaking, (b) how to steer digitalization in a democratically, socially, and ecologically sustainable direction, and (c) how to create a value-centric and public interest-oriented platform society.

\subsection{PUBLIC VALUE-CENTRIC DESIGN: THREE CRITICAL QUESTIONS}

As already hypothesized, in view of current trends it is highly likely that transport services for CAVs will be offered via platforms or platform ecosystems of some sort. It can be assumed that the conflicts arising from these future platforms will be very similar to those existing today. For example, despite the obvious differences, the ongoing legal battles fought between legacy taxi firms and Uber are likely to be no different than those potentially fought with CAV platforms if they threaten the order of existing labor markets, hide under the radar of sectoral legislation, or undermine other aspects of public interest. Given the situation that the "implementation of platforms in society triggers a fierce discussion about private benefit and corporate gains versus public interests and collective benefits," and that "many platforms have grown surprisingly influential before a real debate about public values and common goods could get started" (Dijk et al. 2018: 3), the question that appears to lie at the heart of political commitments and the design of future CAV platforms is how they can incorporate public values and benefit the common good. This will mean that governments and regulators will first have to comprehend the intricate ways in which public values are contested or eroded through the practices of platforms, and then find a broad consensus about the principles that could shape their regulation (Stowel/Vergote 2016). Scholars such as van Dijk et al. (2018) and governmental bodies like the House of Lords (2019) have suggested conceptualizing the principle of a "public value-centric design" of the platform society as a whole. The question lying at its core is: in what kind of society do we want to live in the digital age? This seemingly lofty and philosophical inquiry quickly becomes tangible when coders actually start designing the platform's algorithms. Consciously or unconsciously, they build values into their designs-be they corporate, commercial, or in the public interest.

The first question that arises in this context is: what are public values and which of these values do specific societies want to uphold (see also section 3.3.4)? Moore (1995) describes public value as the value that an organization contributes to society to benefit the common good. As Bozeman (2007) says, the common good can be translated into a number of propositions that are achieved through collective participation in forming a shared set of norms and values. Public values may include privacy, safety, security, accuracy, etc. They may pertain to broader societal effects, such as fairness, accessibility, affordability, inclusiveness, democratic control, or accountability. Also, public values are site- and case-specific, i.e., the values upheld in rural 
Japan may be very different than those in rural Germany. Public values are also ideologically variable and defining them is not the sole privilege of the public sector. Depending on the specificities of the country, this may imply the simple act of rereading and reemphasizing the values already inscribed in the respective nation's constitution. A challenge that would remain for governance is how public values can be advocated and the terms for their implementation negotiated. It is quite evident that there will be no globally universal recipes for their negotiation. Articulating which values are contested by whom and in which context may help to shape the current platform ecosystem in ways that will make it more responsive to public concerns. As mentioned in the section on data-driven urbanism, the governance of platforms will need a whole-of-government approach and the involvement of all relevant stakeholders in society.

The second question that follows is: who will be responsible for anchoring these public values in the platforms and which institutions could oversee the regulation? Besides the need for collaborative action among transnational actors to regulate the global ecosystems of infrastructure platforms, it will be local actors who will play an essential role in keeping an eye on the private sector. An effective way to meet this challenge might be to turn governments into central actors in the platform society. They could themselves become developers of comprehensive platforms centered on public values and collective goals, such as aspired to by the local government of São Paulo (see 3.3.2). Overseeing the regulation can perhaps also be undertaken by independent third-party institutions like civic watchdogs installed by civil society.

The third question is: how can public values be anchored in platforms? The main concern of a value-centric design of the platform society is how to retool the current platform ecosystem by tilting its underlying mechanisms toward "societal valorization" (Dijk et al. 2018:146). This broadly entails redefining the meanings assigned to the technology, implying that the action needed will be as much technological as sociopolitical. Since the 1980 s schools of thought-such as science and technology studies (STS), actor-network theory (ANT), and social construction of technology (SCOT)-have pointed to the effects of broader societal factors in the development of science and technology (Pinter 2008). Contrary to technological determinism, they have shown with different theoretical underpinnings how technology is shaped by complex interactions between numerous vectors of interest and trajectories of change. In this coevolutionary process, the pace of digitalization-mainly driven by corporate players with a technocratic view of the world-is creating an immense lag in the formulation of complementary rationalities and alternative narratives. Efforts to deploy the digital products in a democratic direction will need to broadly anchor democratically endorsed narratives that simultaneously denote technological and ethical elements-such as "ethical technology," "urban commoning," "open data," "opensource ecologies"-in the mindsets of regulators, politicians, stakeholders, and society at large. The technological anchoring and algorithmic translation will follow, or rather, coevolve with the wider context of sociocultural, political and environment discourse (Pinter 2008). It will be the result of a multi-institutional endeavor involving the nexus of public discourse, policy measures, and technological fixes.

\section{CONCLUSION}

This paper has explicated the systemic interlinkages currently unfolding between the emerging practices of the data-driven city and digital platforms. It took MaaS as a case study to exemplify the insecurities arising in the planning of mobility services offered through a digital platform. The choice of these foci for this review was based on the assumption that CAV-based services 
will be offered via digital platforms of some sort in the future and that this will take place in a data-driven city. The article has shown how the urban is being reframed by the conceptualization of the city as a crucible of data that have to be extracted in every way possible (data-driven city). The main tenets of this belief are based on the conviction that all urban processes can and should be measured and monitored, and all urban malfunctions can be treated as technical problems. This understanding of determinism and linear logic has been questioned since the failures of the urban modeling of the 1970s, with the critique of Forrester's model (Gray et al. 1972) and, among others, the classification of Lowrin models (Li/Gong 2016). Also, increasing social diversities are excluded from these models and the general understanding of human behavior is reduced to rational behavior only ("homo oeconomicus").

Further, this paper has shown how the convergence of the physical (spatialities) and the digital (codes) are creating a new kind of cyber-physical reality that is profoundly transforming the academic and managerial imaginaries of the urban. It has been argued that in order to create (socially responsible) mobility services with CAVs, it will be essential to understand the dynamics of these emerging hybrid landscapes. The authors sketched out a mental map of a fourfold process which, according to them, depicts the incessant production of the cyber-physical landscape in the data-driven city. This fourfold movement constitutes (a) the extraction of data from cyber-physical space, (b) the storage of data, (c) the analysis and construction of meaning out of these data and their simultaneous transformation into value in the form of services, and (d) these services augmenting the materialities of everyday life. The socio-technical formations of digital platforms play a key generative role in the production of these cyber-physical landscapes, while MaaS or CAVs play constitutive roles.

Moreover, this paper has demonstrated that digital platforms are shaping the process of digital transformation in profound ways. They are rapidly transforming the entire field of urban services-from news to education, from entertainment to health. Mobility services will play a key role in this newly evolving real-virtual landscape, including services offered around CAVs. It is evident by now that the city of the future will increasingly be built on digital platforms and apps. After effecting radical changes in the business sector, online platforms are now steadily challenging the structures, organizations, and institutions of the state (government); the relationality of power flowing through the networks of state, market, and civil society (governance); and also the techniques, procedures, programs, and strategies of state and non-state agencies that are shaping citizens' conduct (governmentality; Pieterse 2008, Jessop 2004).

While acknowledging the weight of the global framing conditions of politics, technology, the economy, and societal change, the main conclusion of this paper is that the outcome of the digitalization and platformization of public services is neither entirely predetermined, nor is the future locked in by solely entrepreneurial logic or the specter of surveillance. It is still possible for national governments and societies to envision a digital social order that reflects a democratic and equitable direction based on public interest, and to implement these novelties in adaptive manners that enable quick feedbacks of the lessons learnt. This can be achieved if the relevant actors (a) precisely understand the legal engineering and intricate mechanisms of commercially operating platforms, and (b) strive to incorporate public values and collective interests into the architecture of these digital formations, practices, and routines. Promising experiments in the field substantiate this possibility. Public values include the fight against the many forms of digital divide (see 3.3.4).

Policy recommendations will have to move with care and reflexivity, because cutting through the vicissitudes of the emerging cyber-physical world means taking paths as yet untrodden. Seeing the current platform ecosystem being predicated on an architecture shaped overwhelmingly by economic values and corporate interests, and given the complexities of the presumably highly heterogeneous landscape of future service providers operating with diverse logics and inter- 
ests, it is realistic to conceptualize a regulatory framework that clearly defines principles while leaving space for local adaption. The coordinates that anchor the authors' recommendations revolve around the principle of public values. Depending on the political specificities of the country, this may imply the simple act of rereading and reemphasizing the values already inscribed in the respective nation's constitution. The question lying at the center of political commitment and the critical design of future platforms is: how can platforms incorporate locally negotiated public values and benefit the common good? The main lesson learned from the global discourse around digital platforms is that while platforms may enhance personalized benefits and economic gain, they simultaneously put pressure on collective means and public services. The fact that the activities of platforms do not automatically translate into public benefits is the main issue of contention. Public values are at the center of a struggle over a more equitable and democratic platformization of society as a whole, of which mobility, health, education, and other aspects of urbanism are subsets. From this it can be inferred that the key concerns for new governance models for CAV platforms will revolve around the following questions: (a) how will online platforms penetrate a specific transport sector, (b) how are the sectoral platforms embedded in the platform ecosystem as a whole, (c) which site-specific public values are identified, (d) how is their implementation negotiated, and (e) who will oversee their regulation? From the perspective of transport planning, a comprehensive approach and dynamic forms of adaptive policy making and-dynamic adaptive planning can address the looming danger that the deployment of personalized transport systems, such as MaaS, or potential future CAV platforms may bring and minimize the risk of decreasing inclusive public transport services or reduced affordability.

Governments have always negotiated with commercial parties to design regulatory frameworks. To build a trustworthy global platform ecosystem, they will have to distribute responsibilities among the market, state, and civil society (Dijk et al. 2018). They will need a multi-stakeholder, multi-sectoral, and, essentially, a multinational approach that will require a rethinking of social contracts based on equality and solidarity on a global scale. If countries want to protect their democratic values, build more equal societies, and if they believe that only the free flow of information can build a healthy society, then creating governance models for a responsible platform society will have to be a key agenda for governments in the 21 st century.

This review made it evident that the myriad manifestations of the digital revolution will not only radically change the imaginaries of the city, but also the foundations of the socio-technical order of human civilization at large. In times of unprecedented corporate power, the digital space-initially conceptualized as a commons-shows signs of becoming both a splintered arena with an unequal distribution of power, resources, and services, and a real-virtual place for geopolitical, ideological, technological, and legal conflicts-carried out mainly between the USA, the European Union, and China. In the maze of competing critical perspectives on the potential of an equitable future for the internet, views mainly oscillate between two poles: those with a pessimistic view based on the belief that on every conceivable front of digital change lingers the superior cunning of a system that is merely reinventing and perpetuating the existing conditions of inequality and exploitation; the other, more optimistic view is based on the belief that after a phase of initial disorientation and legal vacuum when it comes to regulatory mechanisms, rational policy agendas will incrementally stipulate the conditions of the digital world and make it-and by extension the real-virtual space it governs - a more equitable place.

While this paper was being completed, the world was being ravaged by COVID-19. One consequence of this unprecedented magnitude of disruption in the modern world, was unquestionably the rapid acceleration of digitalization. While the world was rapidly moving its activities into the virtual world, the debate on basic human rights flared up, as country after country in the democratic world attempted to suspend citizens' rights to privacy by deploying digital platforms to track and trace infected persons. In rare cases, civil society was involved in the process of 
designing these apps. At the end of the crisis, studies will show which countries could both respond aptly to the crisis and inscribe democratic values into their spontaneous digital responses. In late March 2020, while the virus was in full swing, a UK delegate to the UN's International Telecommunications Union (ITU) said: "Below the surface, there is a huge battle going over what the internet will look like" (FT 2020). It will be of utmost importance to bring this battle to the surface of public discourse and create a broad and constructive debate on the future of the cyber-physical world. The stakes are high: Do we want a greener and fairer world or do we accept a more unequal one? Do we want an urbanized world of openness and transparency or a world of surveillance and authoritarian control?

\section{LITERATURE}

Annany, M., and K. Crawford. 2016 (2018). "Seeing without knowing: Limitations of the transparency ideal and its application to algorithmic accountability," in New Media \& Society (20) 3, https://doi. org/10.1177/1461444816676645.

Aridi, A., and U. Petrovčič. 2020. "How to regulate Big Tech?", in 'Future Development' blog of the Brookings Institution and the World Bank, Feb 13, 2020, https://www.brookings.edu/blog/futuredevelopment/2020/02/13/how-to-regulate-big-tech/ (July 6, 2020).

Artioli, F. 2018. "Digital platforms and cities: a literature review for urban research," in Cities are back in town. Working Paper (2018) 01, 1-34.

Banerjee, I. 2014. "Smart Cities: A contested marketplace for large corporations and small communities," in Österreichische Ingenieur- und Architekten-Zeitschrift (159) 1, 53-59.

Banerjee I., and I. Fischer-Schreiber. 2015. Digital. Communities 2004-2014. Selected Projects from Prix Ars Electronica. Linz: ARS Electronica. https://www.aec.at/prix/en/kategorien/digital-communities/ (July 6, 2020).

Barns, S. 2018. "Smart cities and urban data platforms: Designing interfaces for smart governance," in City, Culture and Society 12, 5-12. https://doi.org/10.1016/j.ccs.2017.09.006.

Batty, M. 2012. "Smart Cities, Big Data," in Environment and Planning B: Planning and Design (39), 191-193. https://doi.org/10.1068/b3902ed.

Bassoo V., V. Ramnarain-Seetohul, V. Hurbungs, T. P. Fowdur, and Y. Beeharry. 2018. "Big Data Analytics for Smart Cities," in Internet of Things and Big Data Analytics Toward Next-Generation Intelligence, ed. by N. Dey, A. Hassanien, C. Bhatt, A. Ashour, and A. Satapathy, Studies in Big Data, vol. 30. Cham: Springer. https://doi.org/10.1007/978-3-319-60435-0_15.

Beck, U., A. Giddens, and S. Lash. 1996. Reflexive Modernisierung. Eine Kontroverse. Frankfurt am Main: Suhrkamp.

Bostoen, F. 2018. "Neutrality, fairness or freedom? Principles for platform regulation," in Internet Policy Review 7 (1). https://doi.org/10.14763/2018.1.785.

Bozeman, B. 2007. Public Values and Public Interest: Counterbalancing Economic Individualism. Washington, DC: Georgetown University Press.

Bratton, B. H. 2015. The Stack: On Software and Sovereignty. Cambridge, MA/London: MIT Press.

Brenner, N. 1998. "Between Fixity and Motion: Accumulation, Territorial Organization and the Historical Geography of Spatial Scales," in Environment and Planning D: Society and Space (16) 4, 459-481. https://doi.org/10.1068/d160459.

Brenner, N. 2019. New Urban Spaces: Urban Theory and the Scale Question. Oxford: Oxford University Press.

Castells, M. 1996. The Rise of the Network Society. Oxford: Wiley-Blackwell. https://doi.org/ 10.1002/9781444319514.

Chang, S. K. J., H. Y. Chen, and H. C. Chen. 2019. "Mobility as a service policy planning, deployments and trials in Taiwan," in IATSS Research 43 (4), 210-218. https://doi.org/10.1016/j.iatssr.2019.11.007. 
Clement, J. 2020. "Number of mobile app downloads worldwide from 2016 to 2019", in Statista. https:// www.statista.com/statistics/271644/worldwide-free-and-paid-mobile-app-store-downloads/ (July 6, 2020).

Coletta C., L. Heaph, S.-Y. Perng, and L. Waller. 2017. "Data-driven Cities? Digital Urbanism and its Proxies: Introduction," in Tecnoscienza-Italian Journal of Science and Technology Studies 8 (2), 5-18.

Digital Charter UK 2018. "Digital Charter: A response to the opportunities and challenges arising from new technologies," policy paper. https://www.gov.uk/government/publications/digital-charter (July 6, 2020).

Dijck, J. van, T. Poell, and M. de Waal. 2018. The Platform Society: Public Values in a Connective World. New York, NY: Oxford University Press.

EMOTIVE 2020. Homepage. http://emotive.Iboro.ac.uk (Jan 15, 2020).EU Science Hub 2019. The Future of Road Transport-Implications of automated, connected, low-carbon and shared mobility. https://ec.europa.eu/jrc/en/facts4eufuture/future-of-road-transport (July 6, 2020). http://doi. org/10.2760/668964.

European Commission 2015. "Consultation on Regulatory environment for platforms, online intermediaries, data and cloud computing and the collaborative economy," Sep 24, 2015, 5. https://cnnumerique.fr/files/uploads/2015/11/PositionCNNum_ConsultationonplatformsEUCommission.pdf (July 6, 2020).

Fengler, W., and I. Gill. 2019. "A new alphabet for Europe: Algorithms, big data, and the computer chip," in Future Development blog of the Brookings Institution and the World Bank, Apr 18, 2019, https://www.brookings.edu/blog/future-development/2019/04/18/a-new-alphabet-for-europe-algorithms-big-data-and-the-computer-chip/ (July 6, 2020).

Financial Times 2020. "China and Huawei propose reinvention of the internet," in Financial Times, Mar 27, 2020. https://www.ft.com/content/c78be2cf-a1a1-40b1-8ab7-904d7095e0f2 (July 6,.2020).

Finger, M., N. Bert, and D. Kupfer. 2015. "Mobility-as-a-Service: from the Helsinki experiment to a European model?," in FSR Transport (2015) 01. https://doi.org/10.2870/07981.

Getzner M., J. Kadi, A. Krisch, and L. Plank. 2018. "Plattform-Ökonomien: Kennzeichen, Wirkungsweisen und Bedeutung für die Stadtentwicklung," in Jahrbuch des Departments für Raumplanung der TU Wien 2018, ed. by J. Suitner, S. J. Dangschat, and R. Giffinger, vol. 6, 129-144.

Glaeser, E. L. 2011. Triumph of the City: How Our Greatest Invention Makes Us Richer, Smarter, Greener, Healthier, and Happier. New York, NY: Penguin Press.

Gray, J. N., D. Pessel, and P. P. Varaiya. 1972. "A Critique of Forrester's Model of an Urban Area," in IEEE-Transactions on Systems, Man, and Cybernetics (SMC-2) 2, 139-144. https://doi.org/10.1109/ TSMC.1972.4309083.

Haasnoot, M., A. Warren, and J. H. Kwakkel. 2019. "Dynamic Adaptive Policy Pathways (DAPP)," in Decision Making under Deep Uncertainty, ed. by V. Marchau, W. Walker, P. Bloemen, and S. Popper. Cham: Springer, 71-92. https://doi.org/10.1007/978-3-030-05252-2_4.

Hamarat, C., J. H. Kwakkel, and E. Pruyt. 2013. "Adaptive Robust Design under deep uncertainty," in Technological Forecasting and Social Change 80 (3), 408-418. https://doi.org/10.1016/j.techfore.2012.10.004.

Hartikainen, A., J.-P. Pitkänen, A. Riihelä, J. Räsänen, I. Sacs, A. Sirkiä, and A. Uteng. 2019. Whimpact: Insights from the world's first Mobility-as-a-Service (MaaS) system. N.p.: Ramboll. https://ramboll. com/-/media/files/rfi/publications/Ramboll_whimpact-2019 (July 6, 2020).

Haselmayer, M., and M. Jenny. 2017. "Sentiment analysis of political communication: combining a dictionary approach with crowdcoding," in Quality and Quantity 51, 2623-2646. https://doi.org/10.1007/ s11135-016-0412-4.

HSL 2016. "HSL Government Approves Model Contract for Travel Chain Cooperation HSL." https:// www.hsl.fi/uutiset/2016/hsIn-hallitus-hyvaksyi-sopimusmallin-matkaketjuyhteistyosta-9317 (Jan 23, 2020).

Helmond, A. 2015. "The Platformization of the Web: Making Web Data Platform Ready," in Social Media + Society (1) 2. https://doi.org/10.1177/2056305115603080.

House of Lords Select Committee on Communications 2019. Regulating in a Digital World. 2nd Report of Session 2017-19. https://www.regulation.org.uk/library/2019-HoL-Regulating_in_a_Digital_World.pdf (July 6, 2020). 
ITU 2020. "International Telecommunication Union, United Nations Specialized Agency for information and communication technologies," homepage. https://www.itu.int/en/Pages/default.aspx (July 6, 2020).

Jessop B. 2004. "Hollowing out the 'nation state' and multi-level governance," in A Handbook of Comparative Social Policy, ed. by P. Kennett. Cheltenham/Northampton, MA: Edward Elgar, $11-27$.

Jittrapirom, P., V. Caiati, A.-M. Feneri, S. Ebrahimigharehbaghi, M. J. Alonso González, and J. Narayan. 2017a. "Mobility as a Service: A Critical Review of Definitions, Assessments of Schemes, and Key Challenges," in Urban Planning 2 (2), 13-25. https://doi.org/10.17645/up.v2i2.931.

Jittrapirom, P., H. Knoflacher, and M. Mailer. 2017b. "The conundrum of the motorcycle in the mix of sustainable urban transport," in Transportation Research Procedia (25), 4869-4890. https://doi. org/10.1016/j.trpro.2017.05.365.

Jittrapirom, P., V. Marchau, R. van der Heijden, and H. Meurs. 2018a. "Dynamic adaptive policymaking for implementing Mobility-as-a Service (MaaS)," in Research in Transportation Business \& Management (27), 46-55. https://doi.org/10.1016/j.rtbm.2018.07.001.

Jittrapirom, P., V. Marchau, R. van der Heijden, and H. Meurs. 2018b. "Future implementation of mobility as a service (MaaS): Results of an international Delphi study," in Travel Behaviour and Society, 1-59. https://doi.org/10.1016/j.tbs.2018.12.004.

Jittrapirom, P., W. van Neerven, K. Martens, D. Trampe, and H. Meurs. 2019. "The Dutch elderly's preferences toward a smart demand-responsive transport service," in Research in Transportation Business \& Management (30). https://doi.org/10.1016/j.rtbm.2019.100383.

Kamargianni, M., W. Li, M. Matyas, and A. Schäfer. 2016. "A Critical Review of New Mobility Services for Urban Transport," in Transportation Research Procedia (14), 3294-3303. https://doi.org/10.1016/j. trpro.2016.05.277.

Kamargianni, M., M. Matyas, W. Li, and A. Schäfer. 2015. Feasibility Study for 'Mobility as a Service' concept in London. London: UCL Energy Institute. https://doi.org/10.13140/RG.2.1.3808.1124.

Kitchin, R. 2014. "The real-time city? Big data and smart urbanism," in GeoJournal (79), 1-14. https://doi. org/10.1007/s10708-013-9516-8.

Kitchin, R., and G. McArdle. 2016. "What makes Big Data, Big Data? Exploring ontological characteristics of 26 datasets," in Big Data and Society (3) 1. https://doi.org/10.1177/2053951716631130.

Kitchin, R., T. P. Lauriault, and G. McArdle (eds.). 2017. Data and the City. London: Routledge.

Knoflacher, H. 2007. "Success and failures in urban transport planning in Europe-understanding the transport system," in Sadhana 32, 293-307. https://doi.org/10.1007/s12046-007-0026-6.

Kölbl, R., M. Niegl, and H. Knoflacher. 2008. "A strategic planning methodology," in Transport Policy 15 (5), 273-282. https://doi.org/10.1016/j.tranpol.2008.07.001.

Langley, P., and A. Leyshon. 2017. "Platform capitalism: The intermediation and capitalisation of digital economic circulation," in Finance and Society 3 (1), 11-31.

Lempert, R. J. 2019. "Robust Decision Making (RDM)," in Decision Making under Deep Uncertainty, ed. by V. Marchau, W. Walker, P. Bloemen, S. Popper. Cham: Springer, 23-51. https://doi. org/10.1007/978-3-030-05252-2_2.

Leszczynski, A. 2016. "Speculative futures: Cities, data, and governance beyond smart urbanism," in Environment and Planning A: Economy and Space 48 (9), 1691-1708. https://doi. org/10.1177/0308518X16651445.

Leszczynski, A. 2020. "Glitchy vignettes of platform urbanism," in Environment and Planning D: Society and Space (38) 2, 189-208. https://doi.org/10.1177/0263775819878721.

Li, X., and P. Gong. 2016. "Urban growth models: progress and perspective," in Science Bulletin (61) 21, 1637-1650. https://doi.org/10.1007/s11434-016-1111-1.

Mazzucatto, M. 2013. The Entrepreneurial State: Debunking Public vs. Private Sector Myths. London: Anthem Press.

MaaSifest (n.d.). "Mobility as a Service is the future for Mobility." http://www.connekt.nl/initiatief/mobility-as-a-service/ (July 6, 2020).

May, A. D. 2003. A Decision Makers' Guidebook: Developing Sustainable Urban Land Use and Transport Strategies. Brussels: European Commission. https://www.researchgate.net/publication/241745361_A_Decision_Makers\%27_Guidebook (July 6, 2020). 
Moore, M. H. 1995. Creating Public Value: Strategic Management in Government. Cambridge, MA/ London: Harvard University Press.

OECD 2019. "Regulatory effectiveness in the era of digitalisation," June 2019. https://www.oecd.org/ gov/regulatory-policy/Regulatory-effectiveness-in-the-era-of-digitalisation.pdf (July 6, 2020).

Offenhuber, D., and C. Ratti (eds.). 2014. Decoding the City: Urbanism in the Age of Big Data. Basel: Birkhäuser.

Pangbourne, K., M. N. Mladenović, D. Stead, and D. Milakis. 2019. "Questioning mobility as a service: Unanticipated implications for society and governance," in Transportation Research Part A: Policy and Practice (131), 35-49. https://doi.org/10.1016/j.tra.2019.09.033.

Pangbourne, K., D. Stead, M. Mladenović, and D. Milakis. 2018. "The Case of Mobility as a Service: A Critical Reflection on Challenges for Urban Transport and Mobility Governance," in Governance of the Smart Mobility Transition, 33-48. https://doi.org/10.1108/978-1-78754-317-120181003.

Commons Select Committee 2017. "Mobility as a Service: Committee explores transformative potential," in News from Parliament-UK Parliament, (14.11 2017). https://www.parliament.uk/business/ committees/committees-a-z/commons-select/transport-committee/news-parliament-2017/mobility-as-a-service-launch-17-19/ (Jan 23, 2020).

Pieterse, E. 2008. City Futures: Confronting the Crisis of Urban Development. Cape Town: UCT Press.

Pinter, R. 2008. Information Society: From Theory to Political Practice. Budapest: Gondolat uj Madátum.

Pojani, D., and D. Stead. 2015. "Sustainable Urban Transport in the Developing World: Beyond Megacities," in Sustainability 7 (6), 7784-7805. https://doi.org/10.3390/su7067784.

Polis 2017. "Mobility as a Service: Implications for urban and regional transport." https://www.polisnetwork.eu/wp-content/uploads/2017/12/polis-maas-discussion-paper-2017-final_.pdf. (July 6, 2020).

Priisalu, J., and R. Ottis. 2017. "Personal control of privacy and data: Estonian experience," in Health and Technology (7), 441-451. https://doi.org/10.1007/s12553-017-0195-1.

Rudolph, S. 2019. Digitale Medien, Partizipation und Ungleichheit. Eine Studie zum sozialen Gebrauch des Internets. Wiesbaden: Springer VS.

Scott, J. C. 1998. Seeing like a State: How Certain Schemes to Improve the Human Condition Have Failed. Berkeley, CA: Yale University Press.

Shelton, T., M. Zook, and A. Wiig. 2015. "The 'actually existing smart city," in Cambridge Journal of Regions, Economy and Society (8) 1, 13-25. https://doi.org/10.1093/cjres/rsu026.

SMILE 2014. “Pilot operation.” http://smile-einfachmobil.at/pilotbetrieb_en.html (Feb 14, 2020).

Söderström, O. 2014. "Smart city as corporate storytelling," in City (18) 3, 307-320. https://doi.org/10.1 080/13604813.2014.906716.

Söderström, O., and A.-C. Mermet. 2020. "When Airbnb Sits in the Control Room: Platform Urbanism as Actually Existing Smart Urbanism in Reykjavík," in Frontiers in Sustainable Cities (2) 15. https://doi. org/10.3389/frsc.2020.00015

Strowel, A., and W. Vergote. 2016. "Digital Platforms: To Regulate or Not To Regulate?," in European Commission Newsroom. https://ec.europa.eu/information_society/newsroom/image/document/2016-7/uclouvain_et_universit_saint_louis_14044.pdf (July 6, 2020).

Srnicek, N. 2017. Platform Capitalism. Cambridge/Malden: Polity Press.

Tiwana, A. 2014. Platform Ecosystems: Aligning Architecture, Governance, and Strategy. Amsterdam/ Boston, MA/Heidelberg/London/New York, NY/Oxford/Paris/San Diego, CA/San Francisco, CA/ Singapore/Sydney/Tokyo: Morgan Kaufmann.

Townsend, A. M. 2013. Smart Cities: Big Data, Civic Hackers, and the Quest for a New Utopia. New York, NY/London: W. W. Norton \& Company.

Pas, J. W. G. M. van der, J. H. Kwakkel, and B. van Wee. 2012. "Evaluating Adaptive Policymaking using expert opinions," in Technological Forecasting and Social Change 79 (2), 311-325. https://doi. org/10.1016/j.techfore.2011.07.009.

Vayla 2018. "The role of the Finnish Transport Agency in Finnish public transport." https://vayla.fi/web/ en/transport-system/public-transport\#.Xik1VGgzZaQ (Jan 23, 2020).

Walker, W. E., V. A. W. J. Marchau, and J. H. Kwakkel. 2019. "Dynamic Adaptive Planning (DAP)," in Decision Making under Deep Uncertainty, ed. by V. Marchau, W. Walker, P. Bloemen, S. Popper. Cham: Springer, 53-69. https://doi.org/10.1007/978-3-030-05252-2_3. 
Wong, Y. Z., D. A. Hensher, and C. Mulley. 2020. "Mobility as a service (MaaS): Charting a future context," in Transportation Research Part A: Policy and Practice (131), 5-19. https://doi.org/10.1016/j. tra.2019.09.030.

Zipper, D. 2019. “There's No App for Getting People Out of Their Cars ," Bloomberg CityLab, 13.11.2019, https://www.citylab.com/perspective/2019/11/mobility-app-transit-options-ridesharing-bike-carownership/601858/ (Feb 14, 2020).

Open Access This article is licensed under the terms of the Creative Commons Attribution 4.0 International License (http://creativecommons.org/licenses/by/4.0/), which permits use, sharing, adaptation, distribution and reproduction in any medium or format, as long as you give appropriate credit to the original author(s) and the source, provide a link to the Creative Commons licence and indicate if changes were made.

The images or other third party material in this article are included in the chapter's Creative Commons licence, unless indicated otherwise in a credit line to the material. If material is not included in the chapter's Creative Commons licence and your intended use is not permitted by statutory regulation or exceeds the permitted use, you will need to obtain permission directly from the copyright holder.

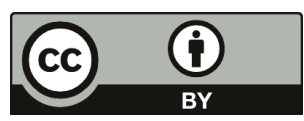

